\title{
Local exposure to inequality among the poor increases support for taxing the rich *
}

\author{
Melissa Sands ${ }^{\dagger} \quad$ Daniel de Kadt ${ }^{\ddagger}$
}

June 25, 2019

\begin{abstract}
How does local economic inequality affect the preferences and behaviors of the poor? We present a placebo-controlled field experiment conducted in Soweto, South Africa, that randomly varies exposure to inequality in low socio-economic settings. We find that willingness to sign a petition that calls for higher taxes on the wealthy increases in the presence of a high-status car. To probe the generality of the experimental finding, we combine a representative geo-referenced survey with neighborhood-level censusderived measures of local inequality, a proxy for direct encounters with tangible reminders of economic inequality. Observationally, exposure to inequality among the poor is associated with an increase in support for taxing the wealthy.
\end{abstract}

${ }^{*}$ We thank Megan Bryer for her excellent management of the field experiment. We thank Thembela Manyathi and Prince Mosia for their superb work in implementing the field experiment. We thank Julia de Kadt and the Gauteng City-Region Observatory for making the Quality of Life IV module available to us. We thank Riley Carney, Ryan Enos, Jessica Trounstine, and Kris-Stella Trump for feedback on drafts of this paper. We thank audiences at EGAP 24, UC Merced, UC Berkeley, Stanford University, and the Helen Suzman Foundation for excellent feedback. All errors are our own. The Supporting Information (SI) is available here. The pre-analysis plan for this study is available in the EGAP repository (\#20190122AA). IRB \#UCM2018-168.

†Political Science, University of California Merced, msands2@ucmerced.edu. Both authors contributed equally to this project. Name ordering is rotated for reasons of fairness.

†Political Science, University of California Merced, ddekadt@ucmerced.edu. 


\section{INTRODUCTION}

Inequality is inherently relational. Decades of social psychological research demonstrate the importance of social comparison in general attitude formation (Festinger, 1954; Tajfel, 1981). More recent work in political science shows that inducing individuals to feel greater social distance from the wealthy increases support for social spending and redistribution (Condon and Wichowsky, 2019). But when and how do these processes occur in the real world, and what consequences do they have for people's revealed redistributive preferences and behaviors? In this paper we use field-experimental and observational evidence from what is widely regarded as the world's most unequal democracy to show that real-world local exposure to inequality encounters with tangible reminders of economic disparity - increases people's willingness to act in support of redistributive taxation of the wealthy.

A new body of research argues that real world 'micro-environments' of economic inequality affect momentary costly political behaviors (Sands, 2017). We hypothesize that everyday experiences of inequality shape people's redistributive preferences and behaviors. Indeed, research in social psychology suggests that people are exposed to inequality every day through social class signals (Kraus et al., 2012). Yet studies of real-world local exposure to inequality - actual encounters or experiences that make economic disparities more salient - are rare because of data constraints and the difficulty of manipulating the salience of economic inequality in people's actual lived environments. Even less is known about how these processes work for the world's poor, a population that remains remarkably understudied given inequality's pernicious effects.

We fill these gaps by studying lower socio-economic status (SES) people in South Africa. First, we analyze a placebo-controlled field experiment designed to organically mimic real-world local exposure to inequality. Working in low income neighborhoods of Soweto, Johannesburg, we manipulate a salient everyday signal of inequality: we randomize the presence of a high status car. To measure how individuals' support for taxing the wealthy changes, we gauge policy support with a petition calling for a tax on the wealthy in aid of redistribution. We find that passersby, who in this context are typically low SES individuals, are roughly 11 percentage points more likely to sign the petition in the presence of inequality cues, net of the experimental placebo effect.

Second, we analyze highly local measures of economic inequality at the immediate neighborhood level, connected to geo-referenced survey responses. These data allow us to test whether our findings extend beyond our experiment. The neighborhood inequality measures are derived from South Africa's most recent census, and are constructed from data even more fine-grained than publicly available U.S. census data on 
household economic status, referring to neighborhoods of roughly 500 people. The geo-referenced survey is a representative sample of people living in South Africa's most populous province, Gauteng, which is home to 14.7 million people, and includes greater Johannesburg and thus our experimental sites in Soweto. Focusing again on those of low SES, we find that, as in the field experiment, local exposure to inequality proxied by our measure of neighborhood inequality is positively associated with support for taxing the wealthy as a means to rectify economic disparities. Using this data we then further explore social comparison processes as a potential mechanism.

\section{LOCAL EXPosure to INEQUALITY}

Inequality is systematically associated with negative outcomes, both social and economic (Wilkinson and Pickett, 2009). Unequal societies have worse physical and mental health (Burns et al., 2014; Messias et al., 2011), lower levels of general well-being (Posel and Casale, 2011; Oishi et al., 2011; Schneider, 2016), higher crime rates (Hsieh and Pugh, 1993), more social distrust (Delhey and Dragolov, 2013), and even diminished political engagement (Solt, 2008). These well-documented associations likely stem in part from behavioral and psychological processes that occur at the individual-level. ${ }^{1}$

A rich tradition of experimental research assesses these processes by manipulating information about levels of national and sub-national inequality, or by manipulating individuals' relative position in those distributions. Such information - about overall inequality and one's place in the distribution - has been shown to alter a range of survey responses and laboratory behaviors. Information about inequality appears to lower levels of generosity (Côté et al., 2015) and cooperation (Nishi et al., 2015), increase status anxiety and risk-taking (Mishra et al., 2015; Payne et al., 2017), shape beliefs about inequality and economic opportunity (McCall et al., 2017; Davidai, 2018), suppress trust in government (Kuziemko et al., 2015), increase support for organized labor (Kane and Newman, 2017), increase beliefs in the legitimacy of inequality (Benabou and Tirole, 2006; Trump, 2017) and, under certain conditions, affect support for redistribution. ${ }^{2}$

But outside of laboratory interventions by researchers, how are do people encounter reminders of inequality in the real world? We argue that people experience inequality in local settings, or micro-environments. By this we mean typically very small-scale situations or settings in which one's status is thrown into sharp relief against a proximate other. This could occur in different ways, depending on one's status and lived environment. For the very poor, it may mean encountering symbols of unattainable wealth - designer clothing

\footnotetext{
${ }^{1}$ See Buttrick and Oishi (2017) and Piff et al. (2018) for a review.

${ }^{2}$ See Trump (2019) for a review of this new literature.
} 
and jewelry or expensive cars, for example. Analogously, in a field experiment, Sands (2017) shows that affluent white individuals become less supportive of a redistributive public policy when they encounter visibly poor white men in wealthy neighborhoods. And relatedly, DeCelles and Norton (2016) find that walking past a first class cabin on an airplane is associated with antisocial behaviors. Consistent with this idea, there is mounting evidence from social psychology that people are indeed made aware of economic inequality on a daily basis through social class signals, which provide information about relative socioeconomic and inter-group status (Kraus et al., 2012, 2017; Piff et al., 2018). Research in political science also suggests that people are aware of inequality in their local environment, and that these effects of these signals are likely conditional on SES (Brown-Iannuzzi et al., 2017), and may be especially pronounced for the poor (e.g. Kawachi and Kennedy, 1999; Newman et al., 2018). Relatedly, there is growing empirical evidence that local demographic context shapes political behaviors (Hopkins, 2010; Kasara, 2013; Robinson, 2017; de Kadt and Sands, 2019).

Taking these insights together, we experimentally induce exposure to inequality in low SES subjects' natural environments. This allows us to capture reactions to experiences of local inequality, and test for effects on preferences and behaviors. We use this experimental approach because it closely mimics the real world processes we wish to uncover, yet allows us to carefully control what occurs. A further advantage is that demand effects or social desirability biases are likely implausible, making the external validity of the experiment more likely. Similarly, we document an actual, costly expression of policy preferences by asking subjects to sign their name to a petition. Petition signing is a meaningful public form of political participation (Carpenter and Moore, 2014) and may also serve as a gateway to other forms of engagement (Parry et al., 2012).

While we are not the first to study local inequality, extant observational research tends to focus on relatively large units of geography rather than one's immediate environment. By conceptualizing local exposure to inequality as micro-environments of inequality that people experience directly every day, effects should be highly contingent on individuals' daily experiences. Potentially as a result of economic segregation, individuals tend to have inaccurate perceptions of current levels of wealth inequality (Norton and Ariely, 2011; Niehues, 2014; Condon and Wichowsky, 2019). Likewise, those residing in a highly unequal but segregated cities may be unaware of broader conditions (Johnston and Newman, 2016). Consistent with this, our empirical results suggest that exposure to inequality at very local levels has effects that are distinct from those that occur at a more distal level. 


\section{The South African Context}

Much of the research on the psychological effects of inequality focuses almost exclusively on advanced industrialized democracies, such as the United States and Western Europe. Exceptions include a handful of observational studies and survey experiments. In Mexico, Phillips (2017) shows that municipal-level income inequality is associated with the presence of vigilante organizations, due to poorer citizens' feelings of relative deprivation in terms of security. In the South African context, Pellicer et al. (2018) use a survey experiment to manipulate beliefs about the inevitability of inequality, and show that demands for redistribution are indeed sensitive to these beliefs. Finally, the literature on the association between inequality and subjective well-being includes some evidence of this relationship in developing contexts (Cheung, 2016; Reyes-García et al., 2018). These notable exceptions aside, studies - and especially field experiments - that directly examine the behavioral implications of exposure to inequality are rare.

Though the behavioral implications of exposure to inequality are not unique to any particular country, South Africa is an important and informative setting for exploring how it affects beliefs and behaviors. South Africa is widely regarded as one of the most unequal countries in the world (The World Bank, 2019). This economic inequality is closely tied to, though is by no means exclusively driven by, racial inequality. The notorious apartheid regime, which lasted from 1948 through 1991, created profound socio-economic legacies for the country. The various policies that under-girded the regime's philosophy of "separate development" led to what are seemingly insurmountable inequalities in terms of incomes and wealth (Seekings and Nattrass, 2008; Leibbrandt et al., 2012), educational attainment (Fedderke et al., 2000; Spaull, 2013), healthcare (Coovadia et al., 2009; Ataguba et al., 2015), and more. The World Bank estimates that, in the 2008-2015 period, South Africa's top 1\% owned approximately $71 \%$ of all assets, while the bottom 60 percent owned only $7 \%$, and a full $40 \%$ of South Africans live below the national lower-bound poverty line of (roughly) 52 USD per person per month (Sulla and Zikhali, 2018). Apartheid also created profound spatial inequality (Christopher, 1994, 2002), the social and political implications of which persist decades after its fall (Mattes and Piombo, 2001; Ferree, 2006; McLaughlin, 2007; Mclaughlin, 2008; Ferree, 2010).

Though economic inequality between race groups has helped to propel South Africa's national Gini coefficient to over 0.6, large inequalities exist even within race groups. By 2001, less than a decade after apartheid, within-race-group inequality was estimated to account for two-thirds of South Africa's total inequality (Whiteford and Van Seventer, 2000), with a black-only Gini coefficient estimated at 0.59 in 2000 (Van der Berg et al., 2004). This figure has grown steadily since the mid-1970s, with a sharp upward tra- 
jectory after the end of apartheid, owing to new, but highly unequal, opportunities for black South Africans, combined with limited economic growth (Nattrass and Seekings, 2001; Southall, 2016).

Given this context, we elect to largely set aside the racial component of inequality in South Africa, not because it is unimportant, but because it adds excessive complexity. That is a non-trivial choice inequality and race are intimately tied together in South Africa - and yet we feel it is necessary. To that end, our implementing fieldworkers were black South Africans, and the research sites selected were nearhomogeneously black neighborhoods in Soweto. Experimentally, this eliminates the confounding presence of race, but also maintains the realism of our experimental intervention. South Africa's poorest neighborhoods tend to be almost exclusively non-white, and the presence of whites in these places a rare occurrence.

\section{The Field Experiment}

Our experiment exposed predominantly black, low SES South Africans in low SES neighborhoods to microenvironments of inequality. We randomized the presence of a high status car, a BMW 3-Series, as individuals were approached by a petitioner asking them to support a redistributive policy. ${ }^{3}$ We directly measured subjects' willingness to sign the redistributive petition or their willingness to sign an unrelated placebo petition. The research design, protocols, hypotheses, and analyses were pre-registered at EGAP (\#20190122AA) prior to data analysis.

The experiment was conducted in Soweto, in the Gauteng province of South Africa, over the course of several weeks in November 2018 through January 2019. We selected seven experimental sites with high pedestrian density, all of which were were predominantly black. As our study was designed to test the effect of exposure to inequality among specifically poorer people, Soweto represented an ideal study environment. The average median annual household income in these neighborhoods is R32,000 (2,253.01 USD per year, or 6.17 USD per day) (from 2011 census, details in SI), or half the annual median household income for black South Africans. It is safe to say that most of our respondents are lower-income individuals. Our choice to focus on pedestrians further increased the likelihood that our sample was of relatively low SES. As in many less wealthy countries, South Africans who walk are more likely to be poor, traveling on foot or via public transit for lack of access to private vehicles (Dewar, 2000).

Based on a pre-determined randomization schedule, a confederate would park, leave, or remove the car from a designated roadside space every 20 minutes, creating a micro-environment of inequality so long

\footnotetext{
${ }^{3}$ At time of writing the car cost seven times the annual household income of the average black South African (StatsSA, 2011b).
} 


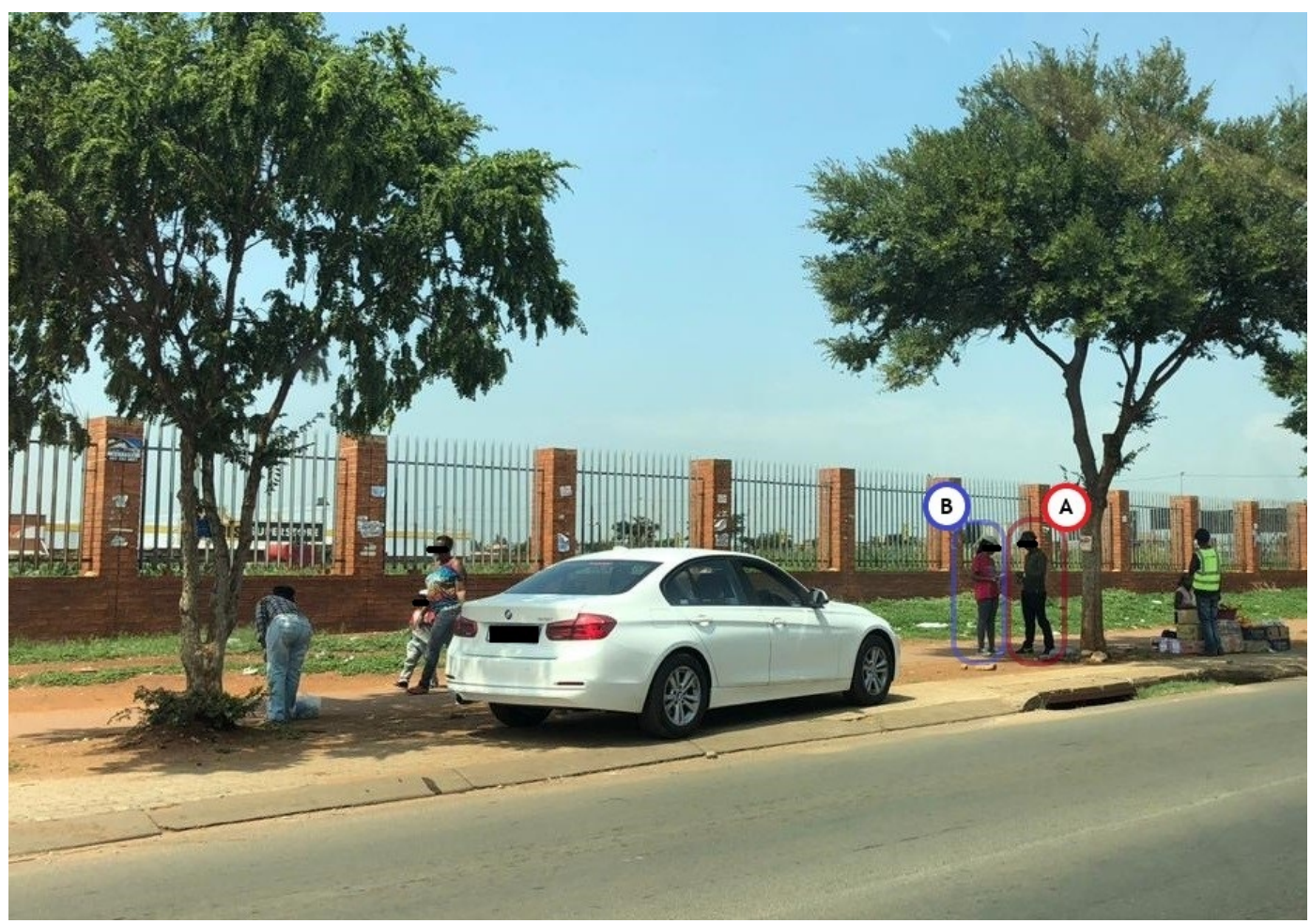

Figure 1: Experiment in progress. The petitioner (A) approaches a subject (B) after the subject passes car.

as the car was present. In South Africa luxury cars are a canonical highly-visible symbol of high SES (Langa and Kiguwa, 2013), and the presence of these cars in Soweto is not extremely uncommon, such that the manipulation appeared natural. The petitioner, holding a clipboard and pen and stationed near the designated parking spot, approached every third adult pedestrian walking toward them, counting left to right. We measure each approached individual's decision to sign, or not to sign, the petition.

The petitioner asked each approached person our primary petition "Would you sign a petition to reduce inequality?" or our placebo petition "Would you sign a petition to reduce nuclear energy?" Once the subject had signed or declined to sign the petition and the interaction was complete, the petitioner unobtrusively used a separate tracking sheet to record whether the approach resulted in a signature, the time the approach was made, and their best guess at the gender (male or female), age (old, middle, young), and race (black African or other) of every person approached. The petitioner and driver were trained, and practiced implementation during a pilot study. The experiment in progress is pictured in Figure 1. The image shows one of the four conditions specified in Table 1, which depicts the full factorial research design and the texts of the two petitions. Analyses of covariate balance, complete study materials for replication, and an anonymized example of the raw data are included in the SI. 
Table 1: Experimental Design

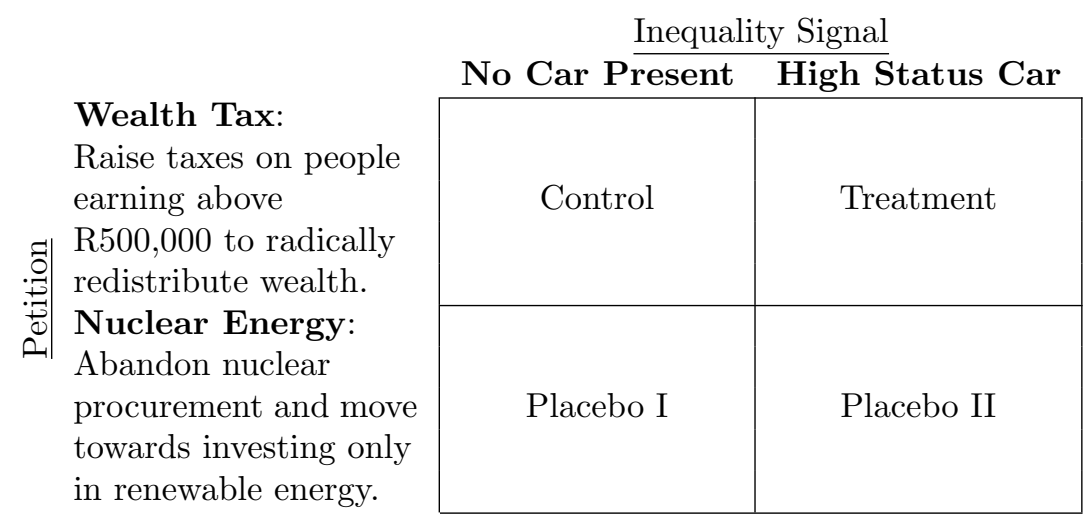

Note: All conditions block randomized at 20 minute time intervals, such that, on any given day, subjects had an equal chance of encountering each condition. Full details of, and replication code for, the randomization procedure is available in the SI.

The placebo petition, which asks the government to abandon nuclear energy in favor of renewable alternatives, is a crucial component of the experimental design, serving two purposes. First, it guards against "scare-off" effects generated by the presence of the car that are not directly related to inequality, potentially masking treatment effects. For example, participants may find it uncomfortable or stressful to stop for any petition in the presence of an expensive car, leading to lower response rates under treatment irrespective of effects on their preferences. Second, observational evidence suggests that inequality suppresses civic and political participation and engagement among the poor (Alesina and La Ferrara, 2000; Solt, 2008; Soss and Jacobs, 2009; Solt, 2010; Anderson and Beramendi, 2012; van Holm, 2019), while experimental evidence suggests that upward social comparisons can suppress political efficacy (Condon and Wichowsky, 2020) and even change people's willingness to accurately report their incomes on surveys (Bush and Prather, 2019). Thus it may be the case that baseline levels of petition-signing are lower in the presence of inequality.

Choosing an appropriate policy issue for the placebo petition is challenging: The petition text must be politically plausible yet unrelated theoretically to experiences of inequality. We believe that nuclear energy is a strong placebo issue for two reasons. First, knowledge about nuclear energy in South Africa is limited (Struwig and Roberts, 2012), so strong associations between nuclear energy and confounding factors related to inequality and taxation are unlikely. Fewer than $10 \%$ of South Africans think the biggest problem with nuclear energy is cost, suggesting the issue is not particularly associated with economic concerns. Second, we see few plausible links between the presence of an expensive car and increased support for nuclear energy. Using our observational data we are able to empirically interrogate these assumptions. In Section 8 we show 
that there is no link between exposure to inequality and self-expressed care for the environment, concerns about climate change, or beliefs about the threat of corruption.

\subsection{Experimental Results}

We present two sets of results, exactly as described in our pre-analysis plan. First, we conduct a simple difference-in-means analysis for individuals $i$ approached to sign the wealth tax petition only:

$$
Y_{i}=\alpha+\beta_{D I M} \operatorname{Car}_{i}+\delta_{d}+\theta \mathbf{X}_{i}+\epsilon_{c}
$$

Where $Y_{i} \in\{0,1\}$ indicates signing the wealth tax petition, $\alpha$ is a global intercept, $\operatorname{Car}_{i} \in\{0,1\}$ indicates the presence of the car, $\delta_{d}$ are day fixed-effects. $\mathbf{X}_{i}$ are optional covariate controls - age, race, and gender captured by the petitioner. Bootstrapped standard errors are clustered at the 20-minute time interval $c$. This difference-in-means analysis simply tests whether response rates in the Control and Treatment conditions (using only those approached to sign the wealth tax petition) are different from one another.

Second, we estimate a difference-in-differences for all individuals in the study, which accounts for the baseline effect of the car on the rate of petition-signing with the placebo petition:

$$
Y_{i}=\alpha+\gamma_{1} \operatorname{Car}_{i}+\gamma_{2} \text { WealthTax }_{i}+\beta_{D I D} \operatorname{Car}_{i} \times \text { WealthTax }_{i} \delta_{d}+\theta \mathbf{X}_{i}+\epsilon_{c}
$$

Where $\operatorname{WealthTax}_{i} \in\{0,1\}$ indicates that the wealth tax (as opposed to nuclear energy) petition was asked, and $\operatorname{Car}_{i} \times$ WealthTax ${ }_{i}$ is the interaction of the presence of the car and the wealth tax petition. $\mathbf{X}_{i}$ are again optional covariate controls. The difference-in-differences analysis essentially subtracts off the difference between Placebo I and Placebo II in Table 1, which captures the baseline effect of the car.

In the difference-in-means setting, $\beta_{D I M}$ is the difference in responses by treatment condition, ignoring all those who were approached to sign the placebo petition. In the difference-in-differences, $\beta_{D I D}$ is this same quantity net of any baseline effect induced by the presence of the car. The point estimates for both $\beta$ parameters (in bold), along with $\gamma_{1}$ and $\gamma_{2}$, are presented in Table 2 .

Considering only those who were asked about the wealth tax petition, the difference-in-means is positive but small, and statistically indistinguishable from zero. As anticipated, this effect is confounded by the suppressive effect of the high-status car: subjects are simply less likely to stop to sign either petition in its presence, regardless of changes to their preferences induced by the treatment. Once we account for this baseline effect by estimating the difference-in-differences, we find respondents are 11 percentage points more 
Table 2: Exposure to Inequality and Support for Wealth Tax

\begin{tabular}{lcccc}
\hline \hline & \multicolumn{4}{c}{ DV: Petition Signed } \\
& $(1)$ & $(2)$ & $(3)$ & $(4)$ \\
\hline Car & $\mathbf{0 . 0 1 4}$ & $\mathbf{0 . 0 1 4}$ & $-0.094^{* *}$ & $-0.095^{* *}$ \\
& $(0.041)$ & $(0.043)$ & $(0.033)$ & $(0.035)$ \\
Wealth Tax & & & $-0.120^{* * *}$ & $-0.125^{* * *}$ \\
& & & $(0.036)$ & $(0.034)$ \\
Wealth Tax $\times$ Car & & & $\mathbf{0 . 1 1 2}^{*}$ & $\mathbf{0 . 1 1 4 ^ { * }}$ \\
& & & $(0.050)$ & $(0.050)$ \\
& & & & \\
Constant & & & & \\
& $0.329^{* * *}$ & $0.346^{* * *}$ & $0.538^{* * *}$ & $0.584^{* * *}$ \\
& $(0.019)$ & $(0.028)$ & $(0.055)$ & $(0.063)$ \\
\hline Day Fixed-Effects & $\checkmark$ & $\checkmark$ & $\checkmark$ & $\checkmark$ \\
Covariates & & $\checkmark$ & & $\checkmark$ \\
Observations & 756 & 756 & 1489 & 1489 \\
\hline \hline
\end{tabular}

Note: Difference-in-means and difference-in-difference OLS regressions of petition signature (binary) on treatment indicators. SEs bootstrapped by 20 -minute time cluster in parentheses.

${ }^{*} p<0.05,{ }^{* *} p<0.01,{ }^{* * *} p<0.001$.

likely to sign the wealth tax petition in the presence of the car. This experimental evidence shows that local exposure to inequality in everyday environments increases support for taxing the wealthy among the poor.

Accounting for this suppressive effect is an important pre-specified element of our study. Still, a concern is that the results are in fact evidence that there is no effect of exposure to inequality on behaviors related to preferences over taxation, but instead an effect on behaviors related to nuclear energy. We find this implausible. The only tenable link between inequality and preferences over nuclear energy would be via concern over corruption: That subjects see an expensive car and are reminded of high-level corruption in the government, connect this to recent government efforts to pursue nuclear energy, and change their behavior. Yet the finding (opposition to nuclear energy decreases in the presence of the car) is inconsistent with such a story. We interpret the result as intended by the design: Pedestrians are roughly 9 percentage points less likely to stop in the presence of an expensive car, which mostly cancels out a roughly 11 percentage point effect of exposure to inequality on support for the wealth tax. We present supplemental analyses in Section 8 to further probe these assumptions. 


\section{The Observational Study}

The observational analog to our experimental intervention requires information about visible inequality in the area where people spend most of their time. In the South African context, especially given high unemployment ( $41 \%$ in Soweto), individuals often spend much of the day in and around their residence. Using very fine-grained data on objective inequality at the residential neighborhood level matched to a geo-located survey, we provide evidence that our experimental results generalize to broader settings and a broader population. We directly test whether objective neighborhood income inequality predicts individuals' preferences over taxing the wealthy. Our experimental intervention manipulates subjective perceptions of inequality in a very local setting. These types of encounters with inequality likely correspond to the objective economic conditions in people's immediate neighborhoods.

We measure inequality at the immediate neighborhood level using South Africa's most recent census (StatsSA, 2011a). We work at the "Small-Area Level" (SAL): each SAL unit contains approximately 5001000 individuals, akin to a small neighborhood. In Gauteng province, which is mostly urban and peri-urban, the median SAL is just 100 square metres. For each SAL, the census counts the number of households within 12 income bins. We rescale those bins and create a household income distribution for every neighborhood in Gauteng, and then collapse the distribution into an (unbiased) Gini coefficient, our measure of local inequality, as presented in Figure 2. We spatially combine this with the provincially representative Quality of Life IV (QOL IV) survey conducted in 2015 by the Gauteng City-Region Observatory (GCRO, 2015). To most closely mirror our experiment, we then subset to those respondents of lower-than-median SES by removing those who score at or above the median of a composite wealth measure based on 10 common household items. ${ }^{4}$ Accounting for missingness, we are left with roughly 10,500 unique low SES survey respondents, matched with census data from the neighborhood in which they live. While the Gini coefficient is a standard measure of inequality used in similar studies (e.g. Kenworthy and McCall, 2007; Kelly and Enns, 2010; Newman et al., 2015), it exhibits some known weaknesses (Allison, 1978), and remains an imperfect observational analog of our experimental intervention. Yet we believe it captures the essence of our treatment: a higher Gini implies a higher the probability of having daily encounters similar to our experimental manipulation. Crucially, our core observational results are not sensitive to our choice of inequality measure. In the SI we re-estimate our main specifications using a variety of alternative inequality measures (Cowell, 2011), and the

\footnotetext{
${ }^{4}$ We use wealth to subset because the household income measure has a high degree of missingness, though this decision is not materially important for the results. All results presented are robust to changing this cutoff for low SES, see the SI.
} 


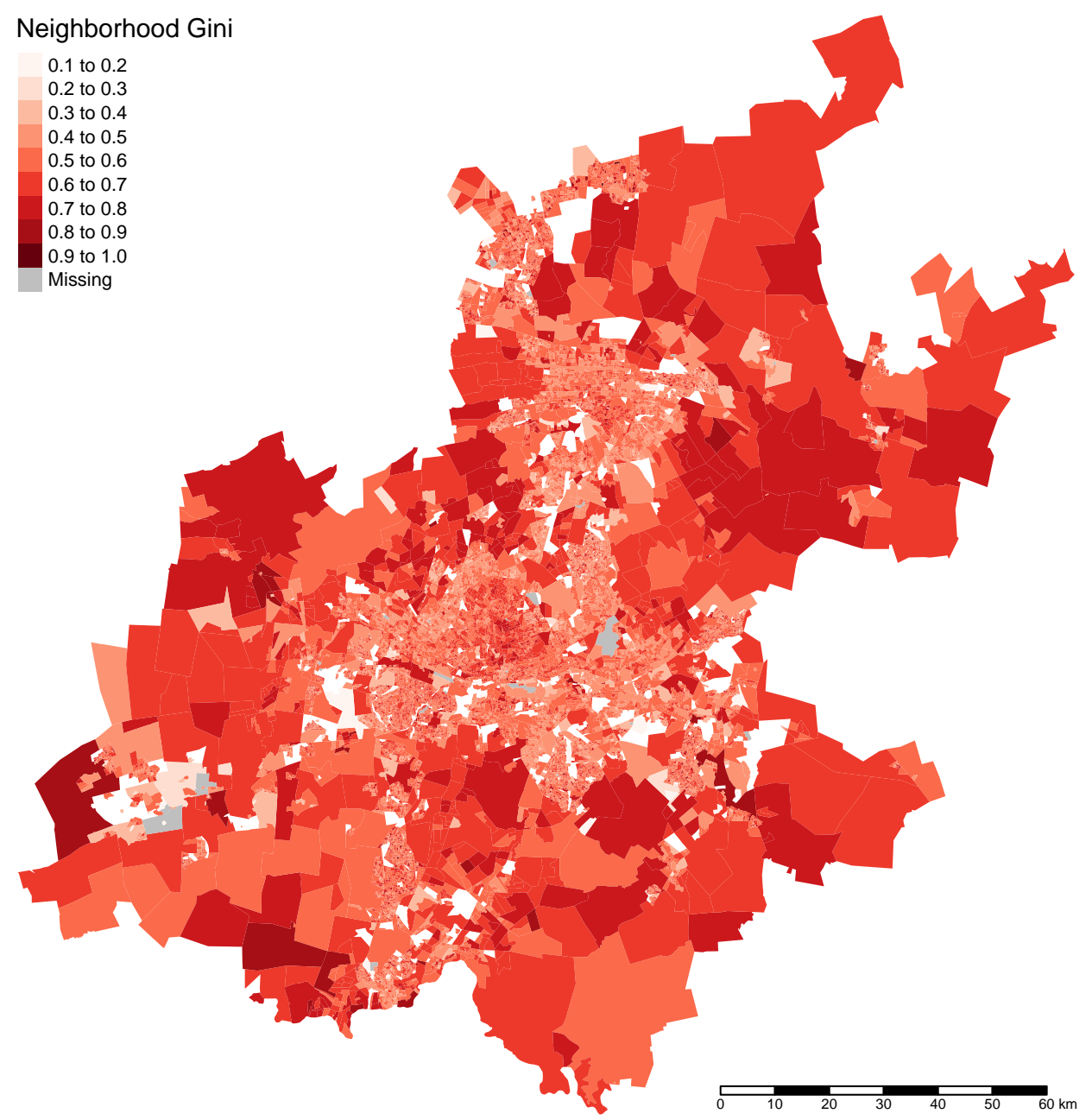

Figure 2: Local Inequality (Gini SAL) in Gauteng Province, South Africa $(N=17,840)$ 
estimates are highly consistent in sign, magnitude, and statistical significance.

\subsection{Observational Analysis and Results}

The QOL IV survey asks "Which of the following approaches do you think would have the biggest impact on inequality?" Five options are given, and we code as 1 any individual who selects "The rich should be taxed more," and 0 if they choose any other option. ${ }^{5}$ As inequality is widely recognized across South Africa as a major issue, we interpret this measure as a survey analog of our petition: Does an individual support taxing the rich so as to reduce inequality?

While we believe the SAL unit of analysis is most directly comparable to our experimental intervention in that it represents an individuals' immediate lived environment, we also replicate our results using two alternative measures of local inequality: the average SAL Gini for $500 \mathrm{~m}$ and $1 \mathrm{~km}$ radii around a rasterized version of the data. Details of these choices, which represent walkable neighborhoods of varying size, are in the SI. We estimate the relationship between our various measures of local inequality and support for taxing the wealthy using OLS:

$$
Y_{i}=\alpha+\beta \text { LocIneq }_{\text {sal }}+\gamma \mathbf{X}_{i}+\delta \mathbf{X}_{\text {sal }}+\epsilon_{\text {sal }}
$$

Where LocIneq is our specific measure of local inequality, and $Y_{i} \in\{0,1\}$ our dependent variable of interest. All specifications are estimated first with only individual level covariates $\mathbf{X}_{i}$ (household income, wealth index, dummied race, sex, age, and the square of age), and then controlling for both individual and SAL level covariates $\mathbf{X}_{\text {sal }}$ (race fractionalization, black, coloured, Indian, and white population shares, and $\log$ average household income), and $\alpha$ as a global intercept. In the South African context, in which easily observable factors like race and age are particularly predictive of political preferences, covariate adjustment is generally worthwhile. Standard errors are clustered by SAL, the level at which "treatment" (local inequality) is assigned (Abadie et al., 2017).

Local inequality is positively associated with the desire to tax the wealthy for redistribution, across all six core specifications, as shown in Figure 3. The point estimates range from 0.08 through 0.15 , for a binary dependent variable. Substantively, across the specifications, a two standard deviation increase in an individual's local inequality is associated with a $1.5-1.7$ percentage point increase in the probability of their

\footnotetext{
${ }^{5}$ See the SI for details on the question wording and other options. One of the other options is "Government should nationalise key sectors of the economy," which in the South African context is similar in spirit to raising taxes on the wealthy. In the SI we discuss this contextual meaning, and then replicate our results using a "broad" definition of taxation that includes this option, and the results only strengthen.
} 


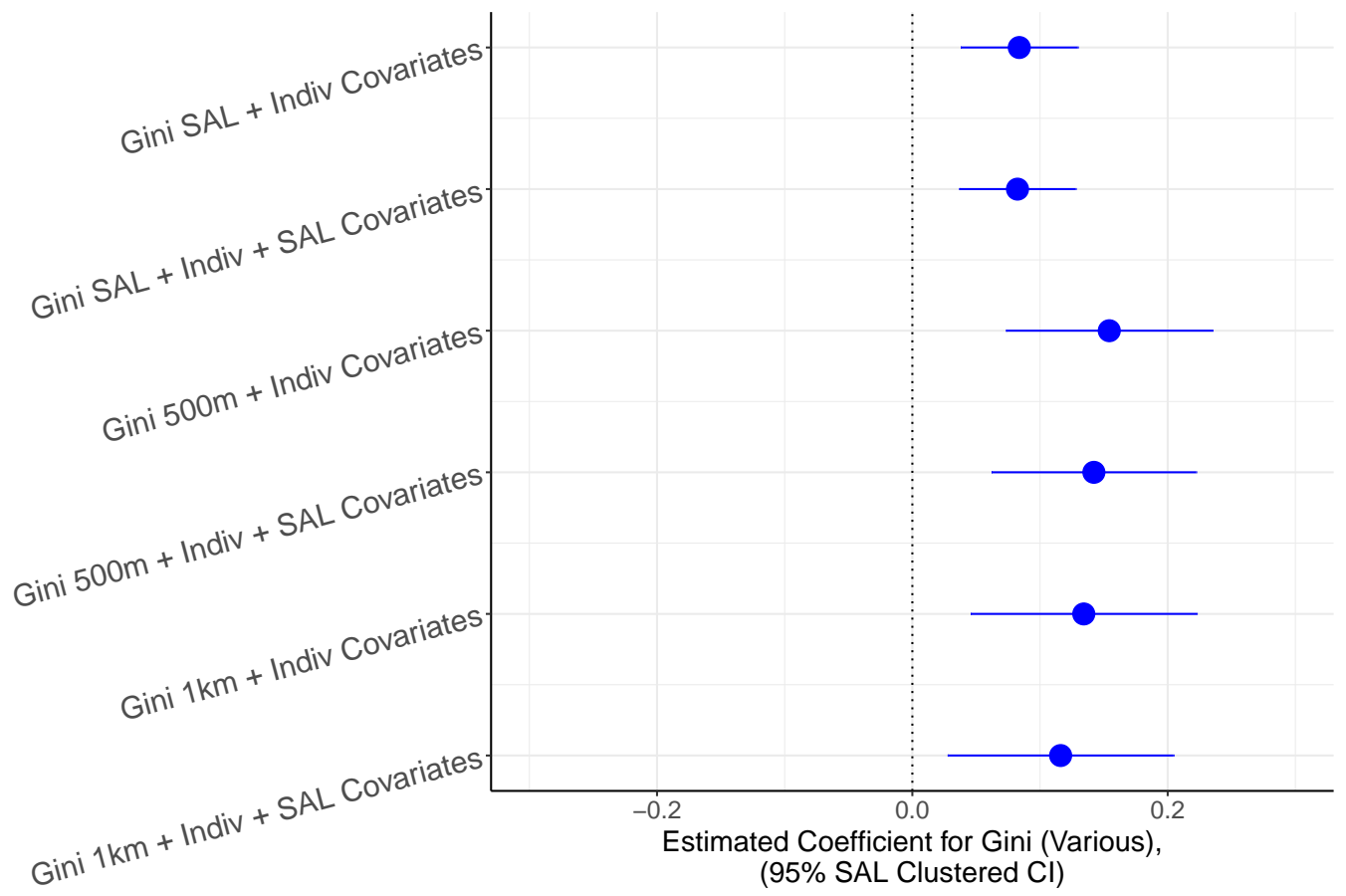

Figure 3: Local Inequality (Gini SAL, Gini 500m Radius, Gini 1km Radius) and Desire to Tax the Wealthy.

Note: Each point represents the estimated association between local inequality and desire to tax the wealthy to reduce inequality from a separate regression estimated at the individual level, using only those with below the median wealth $(N \approx 10,500)$. Results are robust to not controlling for any covariates at all. $95 \%$ confidence intervals account for clustering at the SAL $(M=4,748)$. See the SI for further details and various robustness checks. 
choosing taxing the wealthy as the preferred way to reduce inequality. Unfortunately, directly comparing the effect magnitude caused by a change in Gini coefficient to that caused by our experimental treatment is difficult. This is further complicated by the construction of the survey question used to build the dependent variable, which requires subjects to choose between discrete policy options, rather simply eliciting (strength of) support for one policy. Yet the observational results are consistent with the experimental results.

One concern with these observational analyses is that individuals may have 'sorted' into neighborhoods based on both local inequality and their preferences over redistribution. That is, people who are generally more pro-taxation may also be prone to choose to live in places with higher inequality. While we cannot address this issue fully, we can partially address it by analyzing only those who have lived in Gauteng province for 20 or more years. While this does not address migration internal to the province, it does ensure that a portion of definite 'sorters' are removed from the analysis. Reassuringly, as shown in the SI, our results are largely unchanged among this subset.

The main findings presented here are also robust, both in terms of statistical significance and substantive interpretation, to a range of alternative specifications: if we impute missing covariates using multiple imputation, if we do not adjust for any covariates at all, if we subset to only black South Africans, if we vary the low SES cutoff, and the choice of inequality metric. Details of these exercises are presented in the SI.

\section{Social Comparison as a Potential Mechanism}

Local exposure to inequality appears to increase poor individuals' preferences for taxing the wealthy for redistribution, a result that holds in both a placebo-controlled field experiment and in a broader observational study. What mechanism might drive these effects? We argue that inequality is inherently relational, and that micro-environments of inequality throw one's status in to sharp relief against some proximate other. As such, exposure to inequality likely informs, or even drives, social comparisons, an argument consistent with recent research (Sands, 2017; Condon and Wichowsky, 2019).

To test whether our data are consistent with this social comparison mechanism, we re-estimate our main specifications using a question about subjective status relative to one's neighbors as the dependent variable. Respondents were asked to evaluate whether they are better off, worse off, or the same as those in their neighborhood. The results of this exercise, presented in Figure 4, show that local exposure to inequality is indeed negatively associated with feeling better off than other people in your neighborhood. While this

correlational evidence is consistent with the mediating role of social comparison it is not definitive, and we believe this remains a fruitful area for future research. 


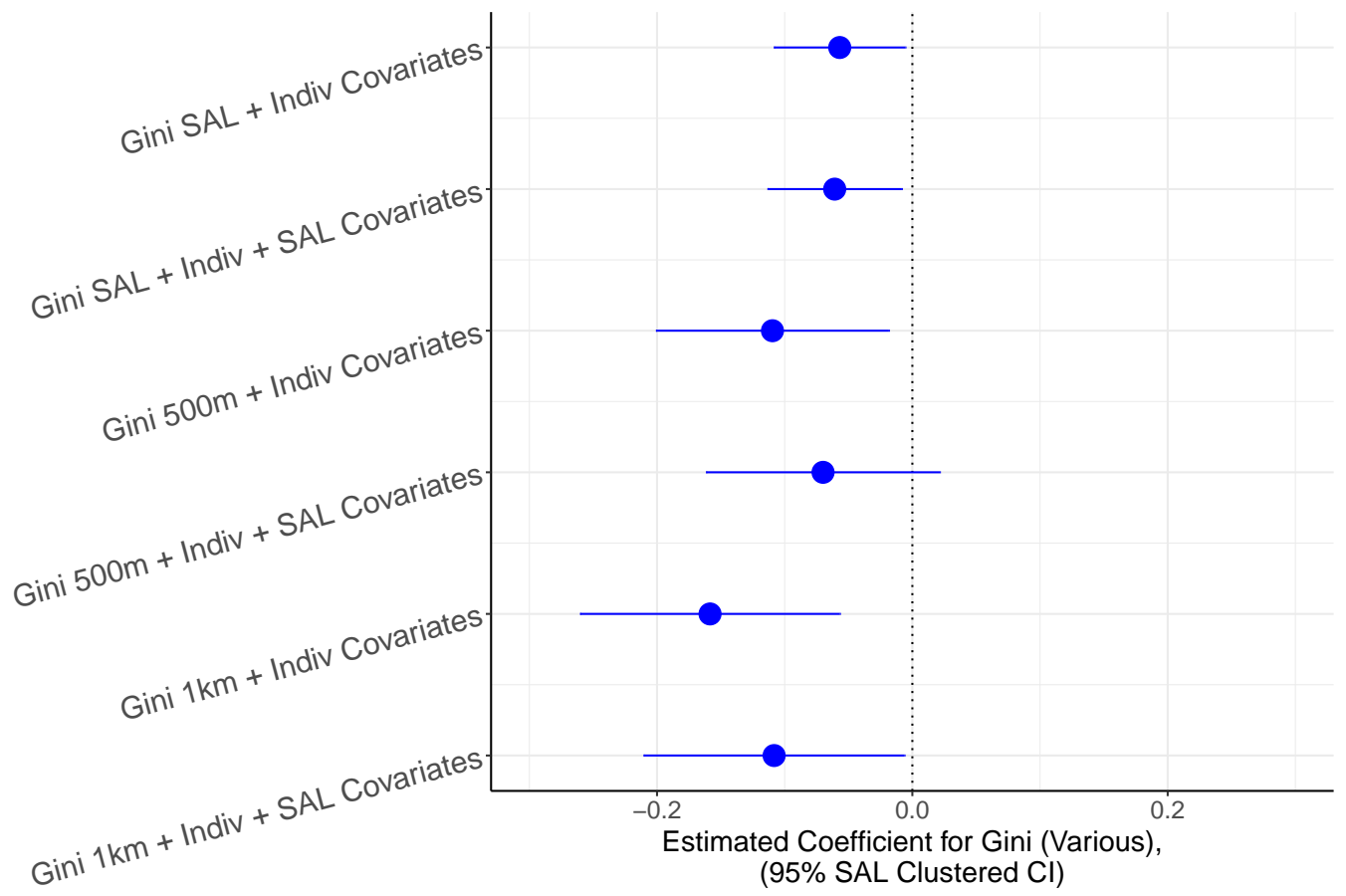

Figure 4: Local Inequality (Gini SAL, Gini 500m Radius, Gini 1km Radius) and Self-Assessed Social Status.

Note: Each point represents the estimated association between inequality and self-assessed social status compared to neighbors from a separate regression estimated at the individual level, using only those with below the median wealth $(N \approx 10,500)$. All results are robust to not controlling for any covariates at all. $95 \%$ confidence intervals account for clustering at the SAL $(M=4,748)$. See the SI for further details and tables. 


\section{Higher Aggregations of Inequality are Not Predictive}

How important is the 'local' dimension of local exposure to inequality? It could be the case that inequality at higher levels - perhaps the city, the province, or even the country - are equally important in shaping people's preferences. One way to test this is by replicating our main specifications for higher aggregations of the Gini coefficient, and we do exactly this using $5 \mathrm{~km}$ and $10 \mathrm{~km}$ radii aggregations. Figure 5 shows negative point estimates that are roughly half the magnitude of the positive estimates when using $500 \mathrm{~m}$ or $1 \mathrm{~km}$ radii, and even appear to weakly attenuate as the aggregation grows higher. None of the results are statistically significant, though this could be on account of noise or effect heterogeneity.

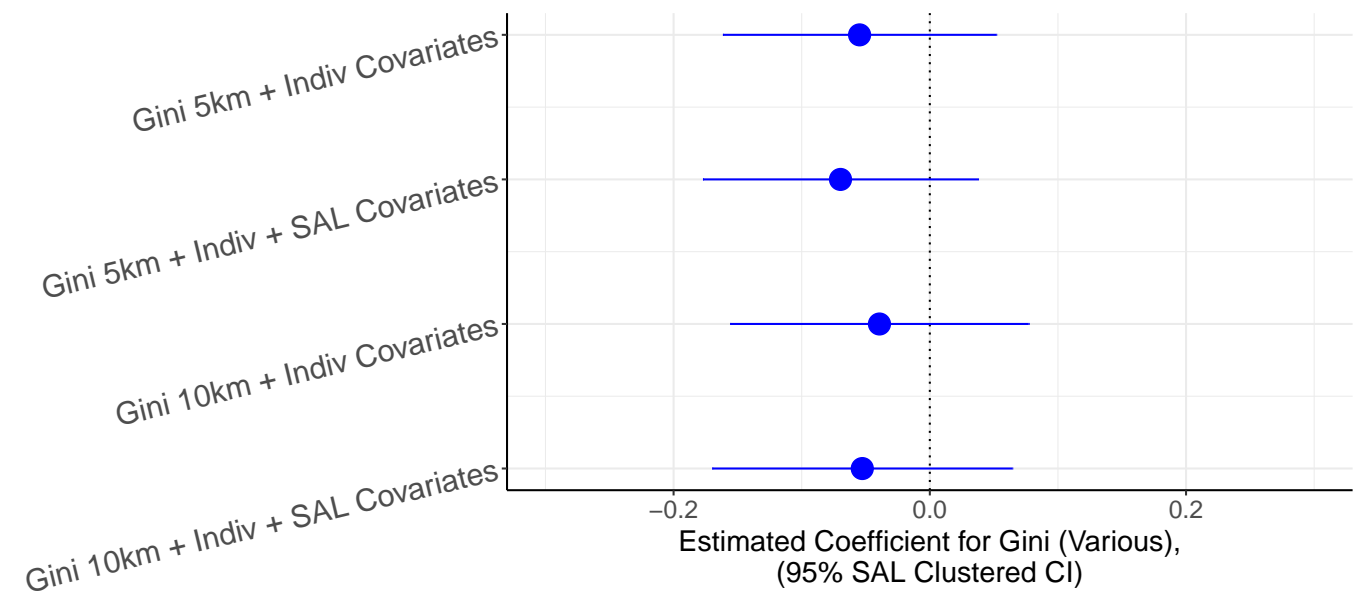

Figure 5: Higher Aggregations of Inequality (Gini 5km Radius, Gini 10km Radius) and Desire to Tax the Wealthy.

Note: Each point represents the estimated association between inequality and desire to tax the wealthy to reduce inequality from a separate regression estimated at the individual level, using only those with below the median wealth $(N \approx 10,500)$. All results are robust to not controlling for any covariates at all. $95 \%$ confidence intervals account for clustering at the SAL $(M=4,748)$. See the SI for further details and tables.

These findings are generally consistent with the idea that the causal power of exposure to inequality operates only over smaller, more local, spaces, through experiences like the one our experiment manipulates. The results also leave open the possibility that higher aggregations of inequality may not just mask, but even reverse, estimated associations, consistent with the modifiable areal unit problem (MAUP). 


\section{Evidence the Placebo is Valid}

As noted in our discussion of the experimental design, the use of our placebo petition is premised on the idea that economic inequality should be unrelated to beliefs about nuclear energy and renewable energy. We believe that it is highly unlikely that such a relationship would exist, or that this relationship would manifest in the particular direction necessary to threaten our inferences - that more inequality leads to lower support for renewable energy. The QOL IV survey allow us to test this assumption, and thus the prima facie plausibility of the placebo.
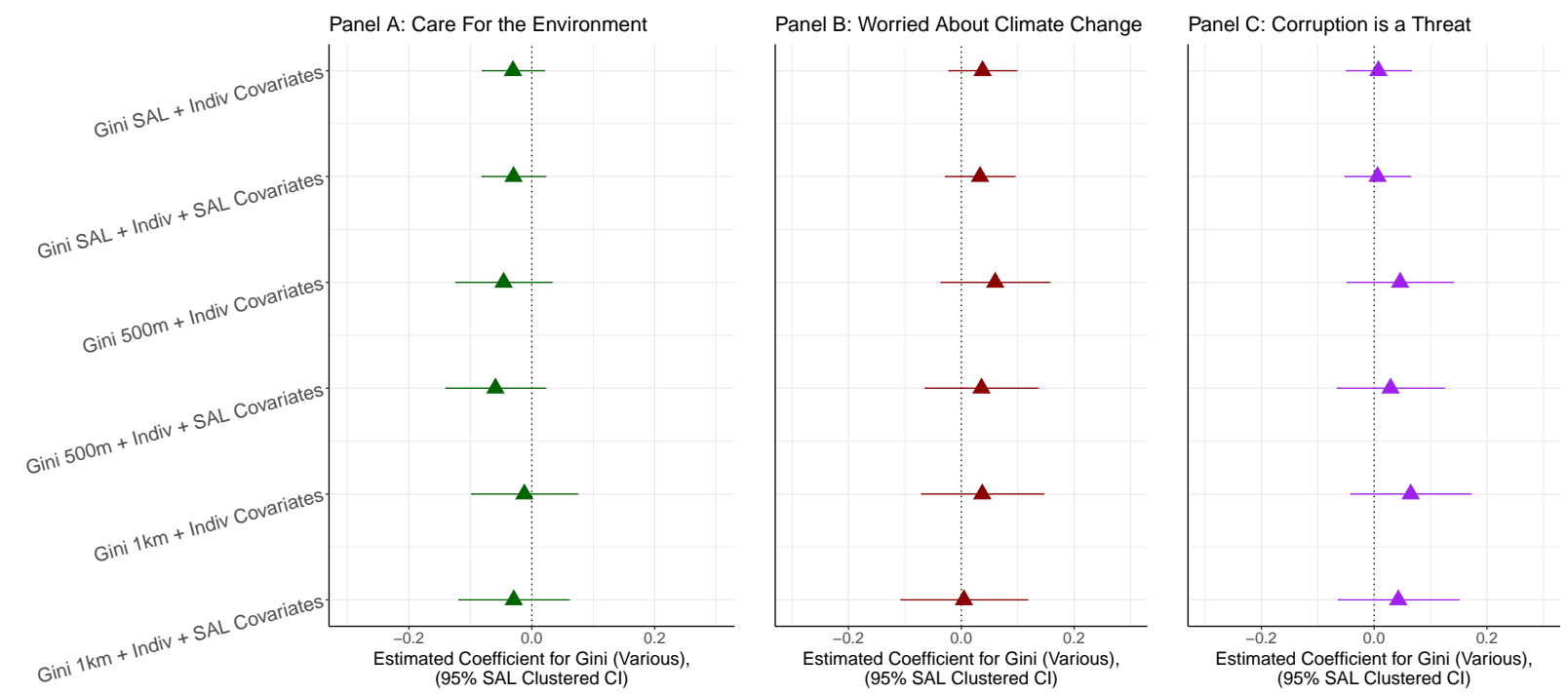

Figure 6: Local Inequality (Gini SAL, Gini 500m Radius, Gini 1km Radius) and Placebo Outcomes.

Note: Each point represents the estimated association between local inequality and one placebo dependent variable, from a separate regression estimated at the individual level, using only those with below the median wealth $(N \approx 10,500)$. Panel A (green) shows results for expressed care about the environment. Panel B (red) shows results for worries about climate change. Panel C (purple) shows concern over threat posed by corruption. Results for panels $\mathrm{B}$ and $\mathrm{C}$ are robust to not controlling for any covariates at all. $95 \%$ confidence intervals account for clustering at the SAL $(M=4,748)$. See the SI for further details and tables.

While the QOL IV survey does not ask directly about nuclear energy specifically, it does include questions about various environmental issues. We test whether local inequality is associated with two dependent variables: expressed care for the environment, and expressed concern over climate change. ${ }^{6}$ Panels A and B of Figure 6 show that these relationships, while not precisely zero, are reasonably close to zero given the same specifications used to produce the results in Figure 3. The point estimates are roughly two to five

\footnotetext{
${ }^{6}$ See SI for details of the question wordings and answer options.
} 
times smaller than the main estimates on taxation, the signs are inconsistent between the two dependent variables (which correlate with each other at $\rho=0.19$ ), and none of the 12 tests presented is statistically significant at any conventional level.

Though this evidence suggests that there is no observational connection between local inequality and beliefs about the environment, corruption remains a plausible mechanism that could link inequality to our placebo issue. South Africa's ruling party, the African National Congress (ANC), has been beleaguered by corruption scandals in the past decade, mostly related to the alleged self-enriching behaviors of former President Jacob Zuma. Some of these scandals related to the procurement of nuclear energy. If South Africans believe that deals to secure nuclear energy are typically corrupt, it is possible that exposure to inequality in our experiment cues corruption, thus changing behaviors related to the support of nuclear energy. Our observational data allows us to test the first part of this chain by exploring the relationship between local inequality and the belief that corruption is a central threat to South African democracy. Reassuringly, Panel $\mathrm{C}$ in Figure 6 shows no evidence of such a relationship. The point estimates are typically two to ten times smaller than our main estimates on tax preferences, and none is statistically significant at any conventional level.

\section{Discussion AND CONCLUSiON}

Across two studies we provide experimental and observational evidence that local exposure to inequality boosts support for redistributive taxation among the poor. First, in a field experiment we show that encounters with tangible, real world symbols of wealth in low income neighborhoods cause individuals to increase their support of a tax on the wealthy. Second, and more generally, local-level economic inequality - a proxy for the type of exposure to inequality manipulated in our experiment - positively and robustly predicts individual support of such taxes.

These findings are consistent with experimental and observational evidence that support for redistribution increases when individuals feel lower in subjective status (Brown-Iannuzzi et al., 2015; Cruces et al., 2013; Condon and Wichowsky, 2019), and decreases when relatively well-off individuals are made to feel higher in status (Côté et al., 2015; Sands, 2017). Exposure to inequality's effect on redistributive preferences may operate by altering perceptions of relative social position, consistent with theories of social comparison (Festinger, 1954) and relative deprivation (Davis, 1959; Crosby, 1976). We find evidence consistent with this causal mechanism.

Because subjective socioeconomic status depends to a great extent on features of an individual's local 
context, studies conducted at relatively high levels of aggregation may mask important variation, and our evidence appears to support this idea (Velez and Wong, 2017). Most observational studies of local inequality use measures at relatively high levels of geographic aggregation, such as U.S. states (Franko, 2016, 2017), counties (Newman et al., 2015; Cheung and Lucas, 2016; Solt et al., 2017; Newman et al., 2018), municipalities (Phillips, 2017; van Holm, 2019), or zip codes (Johnston and Newman, 2016; Page and Goldstein, 2016). One exception is Minkoff and Lyons (2017), who use smaller spatial aggregations, but only consider New York City. In the South African case, Demombynes and Özler (2002) measure local inequality using South Africa's 1996 census, aggregated to the police precinct level, areas that are roughly 100 times larger than the SALs we use in this study. These aggregation choices are problematic due to the MAUP: findings may be driven by the particular boundaries of large spatial units. This problem typically attenuates as units become smaller, thus our high-resolution census-derived measures of local inequality are advantageous. We demonstrate that our observational results are consistent across a range of aggregations, from the neighborhood level up to a $1 \mathrm{~km}$ radius aggregation. Yet moving to much higher levels of aggregation, such as a $5 \mathrm{~km}$ or $10 \mathrm{~km}$ radius, returns point estimates that switch sign but are not statistically distinguishable from zero, suggesting that immediate exposure is an important place to study inequality, rather than the macro-level.

Our findings raise the specter of a classical political economy puzzle: If local exposure to inequality shapes preferences over taxation, why does the "Robin Hood Paradox" persist (Meltzer and Richard, 1981; Lindert, 2004)? Larger, more redistributive welfare states are found in more egalitarian countries, rather than where such institutions are most needed (e.g. Iversen and Soskice, 2009; Rodden, 2019). We believe our argument and our findings suggest that economic segregation is a potential omitted variable. To the extent that the poor live apart from the rich, and that this segregation is more pronounced in more unequal places (Reardon and Bischoff, 2011), we might expect lower levels of support for redistribution than if inequality were more evenly distributed (Condon and Wichowsky, 2019).

While part of our contribution is to examine the psychological effects of inequality salience in a developing country, the phenomenon we describe is unlikely to be unique to these types of contexts. Our findings are consistent with evidence from across the social sciences of inequality's deleterious consequences around the world. It is no surprise that responses to reminders of economic inequality elicit such reactions in the context we study. Humans may in fact be hard-wired to respond to inequality in their immediate environment; consistent with economic models (Fehr and Schmidt, 1999), fMRI studies have uncovered evidence of inequality-aversion in the human brain (Tricomi et al., 2010). Inequality aversion is an innate human behavior, exhibited even in very young children, as early as age three (LoBue et al., 2011). All of 
which coheres with broader evidence that social context and experiences shape beliefs and behaviors (Berger et al., 2008; Enos, 2014, 2016, 2017; Sands, 2017).

Taken together, the evidence presented here suggests a pathway for future research: responses to local inequality among the poor may be conditioned by economic segregation. Differential exposure to disparities may shape political preferences in real and lasting ways. In developed and developing contexts alike the poor tend to live and work apart from more well-off members of society. Thus there may exist vicious cycles in which the demand for the policies to ameliorate economic inequality is suppressed by distortions engendered by local context. 


\section{ReFERENCES}

Abadie, A., S. Athey, G. W. Imbens, and J. Wooldridge (2017). When should you adjust standard errors for clustering? Technical report, National Bureau of Economic Research.

Alesina, A. and E. La Ferrara (2000). Participation in heterogeneous communities. The Quarterly Journal of Economics 115(3), 847-904.

Allison, P. D. (1978). Measures of inequality. American sociological review, 865-880.

Anderson, C. J. and P. Beramendi (2012). Left parties, poor voters, and electoral participation in advanced industrial societies. Comparative Political Studies 45(6), 714-746.

Ataguba, J. E.-O., C. Day, and D. McIntyre (2015). Explaining the role of the social determinants of health on health inequality in south africa. Global health action 8(1), 28865.

Benabou, R. and J. Tirole (2006). Belief in a just world and redistributive politics. The Quarterly journal of economics 121(2), 699-746.

Berger, J., M. Meredith, and S. C. Wheeler (2008). Contextual priming: Where people vote affects how they vote. Proceedings of the National Academy of Sciences 105(26), 8846-8849.

Brown-Iannuzzi, J. L., K. B. Lundberg, A. C. Kay, and B. K. Payne (2015). Subjective status shapes political preferences. Psychological Science 26(1), 15-26.

Brown-Iannuzzi, J. L., K. B. Lundberg, and S. McKee (2017). Political action in the age of high-economic inequality: A multilevel approach. Social Issues and Policy Review 11(1), 232-273.

Burns, J. K., A. Tomita, and A. S. Kapadia (2014). Income inequality and schizophrenia: Increased schizophrenia incidence in countries with high levels of income inequality. International Journal of Social Psychiatry 60(2), 185-196.

Bush, S. S. and L. Prather (2019). Do electronic devices in face-to-face interviews change survey behavior? evidence from a developing country. Research \& Politics 6(2), 2053168019844645.

Buttrick, N. R. and S. Oishi (2017). The psychological consequences of income inequality. Social and Personality Psychology Compass $11(3)$, e12304.

Carpenter, D. and C. D. Moore (2014). When canvassers became activists: Antislavery petitioning and the political mobilization of american women. American Political Science Review 108(3), 479-498.

Cheung, F. (2016). Can income inequality be associated with positive outcomes? Hope mediates the positive inequality-happiness link in rural China. Social Psychological and Personality Science 7(4), 320-330.

Cheung, F. and R. E. Lucas (2016). Income inequality is associated with stronger social comparison effects: The effect of relative income on life satisfaction. Journal of Personality and Social Psychology 110(2), 332.

Christopher, A. J. (1994). The atlas of apartheid. Witwatersrand University Press Publications.

Christopher, A. J. (2002). Atlas of Changing South Africa. Routledge.

Condon, M. and A. Wichowsky (2019). Inequality in the social mind: Perceptions of status and support for redistribution. Journal of Politics.

Condon, M. and A. Wichowsky (2020). The Economic Other: Inequality in the American Political Imagination. University of Chicago Press. 
Coovadia, H., R. Jewkes, P. Barron, D. Sanders, and D. McIntyre (2009). The health and health system of south africa: historical roots of current public health challenges. The Lancet 374(9692), 817-834.

Côté, S., J. House, and R. Willer (2015). High economic inequality leads higher-income individuals to be less generous. Proceedings of the National Academy of Sciences 112(52), 15838-15843.

Cowell, F. (2011). Measuring inequality. Oxford University Press.

Crosby, F. (1976). A model of egoistical relative deprivation. Psychological Review 83(2), 85.

Cruces, G., R. Perez-Truglia, and M. Tetaz (2013). Biased perceptions of income distribution and preferences for redistribution: Evidence from a survey experiment. Journal of Public Economics 98, 100-112.

Davidai, S. (2018). Why do americans believe in economic mobility? economic inequality, external attributions of wealth and poverty, and the belief in economic mobility. Journal of Experimental Social Psychology 79, 138-148.

Davis, J. A. (1959). A formal interpretation of the theory of relative deprivation. Sociometry 22(4), 280-296.

de Kadt, D. and M. L. Sands (2019). Segregation drives racial voting: New evidence from South Africa. Political Behavior.

DeCelles, K. and M. Norton (2016). Flying into a rage: Physical and situational inequality on airplanes predict air rage. Proceedings of the National Academy of Sciences.

Delhey, J. and G. Dragolov (2013). Why inequality makes europeans less happy: The role of distrust, status anxiety, and perceived conflict. European Sociological Review 30(2), 151-165.

Demombynes, G. and B. Özler (2002). Crime and local inequality in South Africa. The World Bank.

Dewar, D. (2000). The relevance of the compact city approach: The management of urban growth in South African cities. In M. Jenks and R. Burgess (Eds.), Compact cities: Sustainable urban forms for developing countries, pp. 209 - 218. Spon Press London.

Enos, R. D. (2014). Causal effect of intergroup contact on exclusionary attitudes. Proceedings of the National Academy of Sciences 111(10), 3699-3704.

Enos, R. D. (2016). What the demolition of public housing teaches us about the impact of racial threat on political behavior. American Journal of Political Science 60(1), 123-142.

Enos, R. D. (2017). The space between us: Social geography and politics. Cambridge University Press.

Fedderke, J. W., R. De Kadt, and J. M. Luiz (2000). Uneducating south africa: The failure to address the 1910-1993 legacy. International Review of Education 46(3-4), 257-281.

Fehr, E. and K. M. Schmidt (1999). A theory of fairness, competition, and cooperation. The Quarterly Journal of Economics 114(3), 817-868.

Ferree, K. E. (2006). Explaining south africa's racial census. Journal of Politics 68(4), 803-815.

Ferree, K. E. (2010). Framing the race in South Africa: The political origins of racial census elections. Cambridge University Press.

Festinger, L. (1954). A theory of social comparison processes. Human Relations 7(2), 117-140.

Franko, W. W. (2016). Political context, government redistribution, and the publics response to growing economic inequality. The Journal of Politics 78(4), 957-973. 
Franko, W. W. (2017). Understanding public perceptions of growing economic inequality. State Politics $\mathcal{E}$ Policy Quarterly 17(3), 319-348.

GCRO (2015). Quality of Life Survey IV. Technical report, Gauteng City-Region Observatory.

Hopkins, D. J. (2010). Politicized places: Explaining where and when immigrants provoke local opposition. American political science review 104(1), 40-60.

Hsieh, C.-C. and M. D. Pugh (1993). Poverty, income inequality, and violent crime: A meta-analysis of recent aggregate data studies. Criminal Justice Review 18(2), 182-202.

Iversen, T. and D. Soskice (2009). Distribution and redistribution: The shadow of the nineteenth century. World Politics 61(3), 438-486.

Johnston, C. D. and B. J. Newman (2016). Economic inequality and us public policy mood across space and time. American Politics Research 44(1), 164-191.

Kane, J. V. and B. J. Newman (2017). Organized labor as the new undeserving rich?: Mass media, classbased anti-union rhetoric and public support for unions in the united states. British Journal of Political Science, 1-30.

Kasara, K. (2013). Separate and suspicious: Local social and political context and ethnic tolerance in kenya. the Journal of Politics 75(4), 921-936.

Kawachi, I. and B. P. Kennedy (1999). Income inequality and health: Pathways and mechanisms. Health Services Research 34 (1 Pt 2), 215.

Kelly, N. J. and P. K. Enns (2010). Inequality and the dynamics of public opinion: The self-reinforcing link between economic inequality and mass preferences. American Journal of Political Science 54(4), 855-870.

Kenworthy, L. and L. McCall (2007). Inequality, public opinion and redistribution. Socio-Economic Review 6(1), 35-68.

Kraus, M. W., J. W. Park, and J. J. Tan (2017). Signs of social class: The experience of economic inequality in everyday life. Perspectives on Psychological Science 12(3), 422-435.

Kraus, M. W., M. L. Rheinschmidt, and P. K. Piff (2012). The intersection of resources and rank: Signaling social class in face-to-face encounters. Facing social class: How societal rank influences interaction, 152172 .

Kuziemko, I., M. I. Norton, E. Saez, and S. Stantcheva (2015). How elastic are preferences for redistribution? evidence from randomized survey experiments. American Economic Review 105(4), 1478-1508.

Langa, M. and P. Kiguwa (2013). Violent masculinities and service delivery protests in post-apartheid south africa: A case study of two communities in mpumalanga. Agenda 27(1), 20-31.

Leibbrandt, M., A. Finn, and I. Woolard (2012). Describing and decomposing post-apartheid income inequality in south africa. Development Southern Africa 29(1), 19-34.

Lindert, P. H. (2004). Growing public: Volume 1, the story: Social spending and economic growth since the eighteenth century, Volume 1. Cambridge University Press.

LoBue, V., T. Nishida, C. Chiong, J. S. DeLoache, and J. Haidt (2011). When getting something good is bad: Even three-year-olds react to inequality. Social Development 20(1), 154-170.

Mattes, R. and J. Piombo (2001). Opposition parties and the voters in south africa's general election of 1999. Democratization 8(3), 101-128. 
McCall, L., D. Burk, M. Laperrière, and J. A. Richeson (2017). Exposure to rising inequality shapes Americans opportunity beliefs and policy support. Proceedings of the National Academy of Sciences, 201706253.

McLaughlin, E. S. (2007). Beyond the racial census: The political salience of ethnolinguistic cleavages in south africa. Comparative Political Studies 40(4), 435-456.

Mclaughlin, E. S. (2008). Racial, ethnic or rational voters? splitting tickets in south africa. Politikon 35(1), 23-41.

Meltzer, A. H. and S. F. Richard (1981). A rational theory of the size of government. Journal of political Economy 89(5), 914-927.

Messias, E., W. W. Eaton, and A. N. Grooms (2011). Economic grand rounds: income inequality and depression prevalence across the united states: an ecological study. Psychiatric Services 62 (7), 710-712.

Minkoff, S. L. and J. Lyons (2017). Living with inequality: Neighborhood income diversity and perceptions of the income gap. American Politics Research, 1532673X17733799.

Mishra, S., L. S. S. Hing, and M. L. Lalumiere (2015). Inequality and risk-taking. Evolutionary Psychology 13(3), 1474704915596295.

Nattrass, N. and J. Seekings (2001). " two nations"? race and economic inequality in south africa today. Daedalus 130(1), 45-70.

Newman, B. J., C. D. Johnston, and P. L. Lown (2015). False consciousness or class awareness? Local income inequality, personal economic position, and belief in american meritocracy. American Journal of Political Science 59(2), 326-340.

Newman, B. J., S. Shah, and E. Lauterbach (2018). Who sees an hourglass? assessing citizens perception of local economic inequality. Research \&3 Politics 5(3), 2053168018793974.

Niehues, J. (2014). Subjective perceptions of inequality and redistributive preferences: An international comparison. Cologne Institute for Economic Research. IW-TRENDS Discussion Paper 2.

Nishi, A., H. Shirado, D. G. Rand, and N. A. Christakis (2015). Inequality and visibility of wealth in experimental social networks. Nature.

Norton, M. I. and D. Ariely (2011). Building a better americaone wealth quintile at a time. Perspectives on Pychological Science 6(1), 9-12.

Oishi, S., S. Kesebir, and E. Diener (2011). Income inequality and happiness. Psychological science 22(9), 1095-1100.

Page, L. and D. G. Goldstein (2016). Subjective beliefs about the income distribution and preferences for redistribution. Social Choice and Welfare 47(1), 25-61.

Parry, J. A., D. A. Smith, and S. Henry (2012). The impact of petition signing on voter turnout. Political Behavior 34(1), 117-136.

Payne, B. K., J. L. Brown-Iannuzzi, and J. W. Hannay (2017). Economic inequality increases risk taking. Proceedings of the National Academy of Sciences 114(18), 4643-4648.

Pellicer, M., P. Piraino, and E. Wegner (2018). Perceptions of inevitability and demand for redistribution: Evidence from a survey experiment. Journal of Economic Behavior 83 Organization.

Phillips, B. J. (2017). Inequality and the emergence of vigilante organizations: The case of Mexican autodefensas. Comparative Political Studies 50(10), 1358-1389. 
Piff, P. K., M. W. Kraus, and D. Keltner (2018). Unpacking the inequality paradox: The psychological roots of inequality and social class. In Advances in Experimental Social Psychology, Volume 57, pp. 53-124. Elsevier.

Posel, D. R. and D. M. Casale (2011). Relative standing and subjective well-being in south africa: The role of perceptions, expectations and income mobility. Social Indicators Research 104(2), 195-223.

Reardon, S. F. and K. Bischoff (2011). Income inequality and income segregation. American Journal of Sociology 116(4), 1092-1153.

Reyes-García, V., A. Angelsen, G. E. Shively, and D. Minkin (2018). Does income inequality influence subjective wellbeing? Evidence from 21 developing countries. Journal of Happiness Studies, 1-19.

Robinson, A. L. (2017). Ethnic diversity, segregation and ethnocentric trust in africa. British Journal of Political Science, 1-23.

Rodden, J. A. (2019). Why cities lose: The deep roots of the urban-rural political divide. Basic Books.

Sands, M. L. (2017). Exposure to inequality affects support for redistribution. Proceedings of the National Academy of Sciences, 201615010.

Schneider, S. M. (2016). Income inequality and subjective wellbeing: Trends, challenges, and research directions. Journal of Happiness Studies 17(4), 1719-1739.

Seekings, J. and N. Nattrass (2008). Class, race, and inequality in South Africa. Yale University Press.

Solt, F. (2008). Economic inequality and democratic political engagement. American Journal of Political Science 52(1), 48-60.

Solt, F. (2010). Does economic inequality depress electoral participation? Testing the Schattschneider hypothesis. Political Behavior 32(2), 285-301.

Solt, F., Y. Hu, K. Hudson, J. Song, and D. . Yu (2017). Economic inequality and class consciousness. The Journal of Politics 79(3), 1079-1083.

Soss, J. and L. R. Jacobs (2009). The place of inequality: Non-participation in the american polity. Political Science Quarterly 124(1), 95-125.

Southall, R. (2016). The new black middle class in South Africa. Boydell \& Brewer.

Spaull, N. (2013). Poverty \& privilege: Primary school inequality in south africa. International Journal of Educational Development 33(5), 436-447.

StatsSA (2011a). South African National Census of 2011. Technical report, Statistics South Africa.

StatsSA (2011b). Statistical Release (Revised): Census 2011. Technical report, Statistics South Africa.

Struwig, J. and B. Roberts (2012). Heart of the matter: Nuclear attitudes in south africa. HSRC review 10(2).

Sulla, V. and P. Zikhali (2018). Overcoming poverty and inequality in south africa: An assessment of drivers, constraints and opportunities. Washington, DC: The World Bank Group. Retrieved on July, 25th.

Tajfel, H. (1981). Human groups and social categories: Studies in social psychology. CUP Archive.

The World Bank (2019). GINI index (World Bank Estimates). https://data.worldbank.org/indicator/ SI.POV.GINI. Accessed: May 23, 2019.

Tricomi, E., A. Rangel, C. F. Camerer, and J. P. ODoherty (2010). Neural evidence for inequality-averse social preferences. Nature 463(7284), 1089. 
Trump, K.-S. (2017). Income inequality influences perceptions of legitimate income differences. British Journal of Political Science, 1-24.

Trump, K.-S. (2019). Public Opinion and Reactions to Increasing Income Inequality. In M. Weir and F. Rosenbluth (Eds.), The New Politics of Insecurity. Social Science Research Council.

Van der Berg, S., M. Louw, et al. (2004). Changing patterns of south african income distribution: Towards time series estimates of distribution and poverty. South African journal of economics 72(3), 546-572.

van Holm, E. J. (2019). Unequal cities, unequal participation: The effect of income inequality on civic engagement. The American Review of Public Administration 49(2), 135-144.

Velez, Y. R. and G. Wong (2017). Assessing contextual measurement strategies. The Journal of Politics $79(3), 1084-1089$.

Whiteford, A. and D. Van Seventer (2000). Understanding contemporary household inequality in south africa. Studies in Economics and Econometrics 24(3), 7-30.

Wilkinson, R. G. and K. E. Pickett (2009). Income inequality and social dysfunction. Annual Review of Sociology 35, 493-511. 